\title{
Alteration of Epileptogenesis Genes
}

\author{
Amy R. Brooks-Kayal,*广 Yogendra H. Raol,* and Shelley J. Russek ${ }^{\ddagger}$ \\ *Division of Neurology, Department of Pediatrics, University of Colorado Denver School of Medicine, ${ }^{\dagger}$ The Children's Hospital, \\ Aurora, Colorado 80045, and ${ }^{\ddagger}$ Laboratory of Translational Epilepsy, Department of Pharmacology and Experimental \\ Therapeutics, Boston University School of Medicine, Boston, Massachusetts 02118
}

\begin{abstract}
Summary: Retrospective studies suggest that precipitating events such as prolonged seizures, stroke, or head trauma increase the risk of developing epilepsy later in life. The process of epilepsy development, known as epileptogenesis, is associated with changes in the expression of a myriad of genes. One of the major challenges for the epilepsy research community has been to determine which of these changes contributes to epileptogenesis, which may be compensatory, and which may be noncontributory. Establishing this for any given gene is essential if it is to be considered a therapeutic target for the prevention or treatment of epilepsy. Our laboratories have examined alterations in gene expression related to inhibitory neurotransmission that have been proposed as contributing factors in epileptogenesis. The $\mathrm{GABA}_{\mathrm{A}}$ receptor mediates most fast synaptic inhibition, and changes in $\mathrm{GABA}_{\mathrm{A}}$ receptor subunit
\end{abstract}

expression and function have been reported in adult animals beginning immediately after prolonged seizures (status epilepticus [SE]) and continue as animals become chronically epileptic. Prevention of $\mathrm{GABA}_{\mathrm{A}}$ receptor subunit changes after SE using viral gene transfer inhibits development of epilepsy in an animal model, suggesting that these changes directly contribute to epileptogenesis. The mechanisms that regulate differential expression of $\mathrm{GABA}_{\mathrm{A}}$ receptor subunits in hippocampus after SE have recently been identified, and include the CREB-ICER, JAK-STAT, BDNF, and Egr3 signaling pathways. Targeting signaling pathways that alter the expression of genes involved in epileptogenesis may provide novel therapeutic approaches for preventing or inhibiting the development of epilepsy after a precipitating insult. Key Words: GABA receptor subunits, epilepsy, epileptogenesis, hippocampus, gene transfer, transcriptional regulation.

\section{INTRODUCTION}

It is clear from the results of research using various animal models and from human retrospective studies that an initial precipitating event such as status epilepticus (SE) can increase the risk of later epilepsy development (epileptogenesis). The process of epileptogenesis is likely to be complex and multifactorial. Determining whether changes in gene regulation that accompany the epileptic condition are consequential to or causative of disease etiology is the major difficulty of research in this area. Many laboratories, including our own, have focused on the role of gene regulation in determining changes in GABA receptor plasticity that occur during the latent period after brain insult and prior to the development of the epileptic state. GABA is the major inhibitory neurotransmitter in the mature brain, and various drugs that enhance GABAergic inhibition are commonly

Address correspondence and reprint requests to: Amy R. BrooksKayal, M.D., Department of Pediatrics, Division of Neurology, University of Colorado Denver, 12700 E, 19th Avenue, Rm P15-4122A, Mail Stop 8605, Aurora, CO 80045. E-mail: brooks-kayal.amy@ tchden.org. used as antiepileptic drugs. Also, drugs that block GABAergic inhibition can induce seizures in animals, further supporting the potential importance of alterations in GABAergic transmission in epileptogenesis.

\section{ROLE OF GABA A RECEPTORS IN EPILEPSY}

Three types of GABA receptors are found in the mature central nervous system: $\mathrm{GABA}_{\mathrm{A}}, \mathrm{GABA}_{\mathrm{B}}$, and $\mathrm{GABA}_{\mathrm{C}}$. Both $\mathrm{GABA}_{\mathrm{A}}$ and $\mathrm{GABA}_{\mathrm{C}}$ are ionotropic receptors; $\mathrm{GABA}_{\mathrm{B}}$ is a metabotropic receptor. Most fast synaptic inhibition in the mature brain is mediated by $\mathrm{GABA}_{\mathrm{A}}$ receptors, whereas slow inhibition is mediated by $\mathrm{GABA}_{\mathrm{B}}$ receptors. $\mathrm{GABA}_{\mathrm{A}}$ receptors are composed of multiple subunit subtypes $(\alpha 1-6, \beta 1-3, \gamma 1-3, \delta, \varepsilon, \pi$, $\theta$, and $\rho 1-3)$ that form a pentameric anion-selective channel. ${ }^{1,2}$ The most common in vivo subunit composition is two $\alpha$, two $\beta$, and one $\gamma$ subunit. There is remarkable receptor heterogeneity, with subtype combinations varying in different brain regions and cell types, and during different times in ontogeny. ${ }^{3-6}$ Different subunit subtypes confer distinct functional and pharmacological properties to the receptors. ${ }^{3}$ 
Prolonged seizures (i.e., SE) result in alterations in the expression and membrane localization of several $\mathrm{GABA}_{\mathrm{A}}$ receptor subunits $(\alpha 1, \alpha 4, \gamma 2$, and $\delta)$ in hippocampal dentate granule neurons. $^{7-9}$ These alterations, which are associated with changes in phasic and tonic $\mathrm{GABA}_{\mathrm{A}}$ receptor-mediated inhibition, and in $\mathrm{GABA}_{\mathrm{A}}$ receptor modulation by benzodiazepines, neurosteroids, and zinc, begin soon after SE and continue as animals become epileptic. $^{7-10}$

Several laboratories have documented changes in $\mathrm{GABA}_{\mathrm{A}}$ receptor subunit composition in human temporal lobe epilepsy (TLE) and in animal models of TLE. $^{7,9,11,12}$ In the pilocarpine model of SE in adult rodents, $\mathrm{GABA}_{\mathrm{A}}$ receptor $\alpha 1$-subunit mRNA expression decreases, $\alpha 4$-subunit mRNA expression increases in dentate granule cells (DGCs) of the hippocampus, and animals uniformly go on to develop the recurrent spontaneous seizures that define epilepsy. ${ }^{7}$ The change in subunit expression correlates with a decreased sensitivity to zolpidem augmentation and increased sensitivity to zinc inhibition of $\mathrm{GABA}_{\mathrm{A}}$ receptor responses. ${ }^{7}$ Similar functional and subunit expression changes have been observed in DGCs isolated from surgically resected hippocampus from patients with intractable TLE. ${ }^{12}$ The changes in $\mathrm{GABA}_{\mathrm{A}}$ receptor subunit expression and function in DGCs of epileptic animals precede the development of epilepsy, suggesting that these changes contribute to the epileptogenesis process. In contrast, neonatal SE (postnatal day 10) in rats results in increased $\mathrm{GABA}_{\mathrm{A}}$ receptor $\alpha 1$-subunit expression and does not subsequently lead to development of epilepsy. ${ }^{13}$

These studies suggest that $\mathrm{GABA}_{\mathrm{A}}$ receptor subunit alterations may be an important component of epileptogenesis. To more directly determine if $\mathrm{GABA}_{\mathrm{A}}$ receptor changes are critical contributors to epilepsy development, we used gene transfer to prevent these $\mathrm{GABA}_{\mathrm{A}}$ receptor subunit changes. To directly test the hypothesis that the expression of higher $\alpha 1$-subunit levels inhibits development of epilepsy after SE, an adeno-associated virus (AAV) gene transfer vector (AAV2), serotype 5, was designed to express a bicistronic RNA that codes for both the $\mathrm{GABA}_{\mathrm{A}}$ receptor $\alpha 1$-subunit and the reporter (enhanced yellow fluorescence protein [eYFP]). ${ }^{14} \mathrm{Ex}$ pression of this RNA was placed under control of the $\mathrm{GABA}_{\mathrm{A}}$ receptor $\alpha 4$-subunit gene (GABRA4) core promoter region, because this was previously shown to be markedly activated in dentate gyrus (DG) after $\mathrm{SE}^{15}$ : activity of the $\alpha 4$ promoter is upregulated after SE, resulting in enhanced $\alpha 1$ expression in DG.

The AAV vector containing either the $\alpha 1 /$ YYFP fused cDNA (AAV- $\alpha 1)$ or the eYFP reporter only (AAVeYFP) was injected into the DG of adult rats, and SE was induced 2 weeks later by intraperitoneal injection of pilocarpine $(385 \mathrm{mg} / \mathrm{kg}) .{ }^{14}$ Rats injected with AAV- $\alpha 1$ showed threefold higher levels of $\alpha 1$-subunits in the DG by 2 weeks after SE compared to the control groups. Rats were continuously video-EEG monitored to determine the latency for development of spontaneous seizures. AAV- $\alpha 1$ injection resulted in a threefold increase in the mean time to the first spontaneous seizure after SE, and only $39 \%$ of AAV- $\alpha 1$ injected rats were observed to develop spontaneous seizures in the first 4 weeks after SE, compared with $100 \%$ of rats receiving sham injections. Because all groups of rats experienced similar SE after pilocarpine injection, these findings provide the first direct evidence that increasing the levels of a single $\mathrm{GABA}_{\mathrm{A}}$ receptor subunit in the DG can inhibit the development of spontaneous seizures after SE. Together, these data support a role for $\mathrm{GABA}_{\mathrm{A}}$ receptor $\alpha$-subunit changes in the process of epileptogenesis.

\section{MECHANISMS REGULATING GABA RECEPTOR SUBUNIT EXPRESSION}

\section{$\alpha 1$ Subunit regulation}

Although viral gene transfer is a promising therapeutic avenue for modifying aberrant gene expression associated with epileptogenesis, producing the optimal level of expression over a prolonged period can be challenging. Another possible approach is to modify the mechanisms regulating gene expression. Recent work in our laboratories has established cAMP response element binding protein (CREB) and inducible cAMP early repressor (ICER) as critical mediators of the $\mathrm{GABA}_{\mathrm{A}}$ receptor $\alpha 1$-subunit mRNA decreases that occur after $\mathrm{SE}$ in the DG. The CREB is a stimulus-induced bZIP transcription factor that is activated by phosphorylation at its Ser 133 site. Phosphorylated CREB (pCREB) dimerizes and binds to cAMP response element (CRE) motifs on promoters that contain the consensus sequence TGACGTCA. ${ }^{16}$ Along with its chromatin regulator, the CREB binding protein (CBP), pCREB upregulates transcription of target genes.

Transcriptional regulation through CREB has been implicated in mechanisms of cell survival, plasticity, and learning and memory paradigms. ${ }^{17}$ Target genes of pCREB include $C R E B$ family members encoding cAMP response element modulator (CREM), ICER, and activating transcription factors. These para- and homologs of CREB also bind CRE elements to modulate the transcription of particular genes. The CREM gene produces many spliced isoforms that can act as transcriptional repressors or activators. One of these repressor forms is ICER, a group of four proteins made from an internal promoter in the CREM gene. ${ }^{18}$ ICER can act as a homodimer at the CRE site or heterodimerize with CREB to directly block CREB-induced transcription.

The human $\alpha 1$ promoter contains a functional CRE, ${ }^{19}$ making CREB and its family members potential regulators of $\alpha 1$ gene expression in epilepsy. Several studies using adult animal models of epilepsy suggest that seizures 
upregulate pCREB or CREM and ICER activity. ${ }^{20,21}$ Our laboratory has found sustained increases in both pCREB and ICER in the DG of the hippocampus, continuing 1-48 hours after pilocarpine-induced SE. ${ }^{22}$ Using chromatin immunoprecipitation and DNA pulldown studies, increased pCREB and ICER binding at the CRE site of $\mathrm{GABA}_{\mathrm{A}}$ receptor $\alpha 1$-subunit gene (GABRAl) were also observed after SE. ${ }^{22}$ Further, in transfected primary hippocampal neurons manipulating CREB and ICER levels showed that overexpression of CREB and ICER together decreases GABRA1 promoter and reporter activity and overexpression of ICER alone decreases the levels of endogenous $\alpha 1$-subunits at the cell surface. ${ }^{23}$ These findings suggest that CREB and ICER are important regulators of seizure-induced GABRA1 changes.

The excessive neuronal activity associated with SE stimulates many different signaling pathways that could result in enhanced phosphorylation of CREB and expression of ICER. ${ }^{24}$ Determining which of these pathways mediates the increase in ICER expression critical for decreased transcription of the $\mathrm{GABA}_{\mathrm{A}}$ receptor $\alpha 1$-subunit is crucial to understanding how crosstalk between different signaling pathways can lead to specific changes in inhibitory neurotransmission. The focus of our studies was on brain derived neurotrophic factor (BDNF) as a potential regulator of ICER, because BDNF expression increases markedly after $\mathrm{SE}^{25-29}$ and because BDNF differentially regulates the abundance of both $\alpha 1$ - and $\alpha 4$ subunits in cultured neurons. ${ }^{29}$ Results demonstrated that BDNF treatment of primary hippocampal neurons in culture produces similar changes in $\alpha$-subunit levels as observed after SE: 24 hours after BDNF treatment, $\alpha 1$ levels decreased $42 \%$ and $\alpha 4$ levels increased $120 \%{ }^{29}$

How does BDNF regulate $\alpha 1$-subunit levels? Surprisingly, it relies on activation of the Janus kinase-signal transducer and activators of transcription (JAK-STAT) pathway that in turn controls the synthesis of ICER, a repressor of GABRA1 transcription. The JAK-STAT pathway is activated by cytokines binding to their specific receptors, resulting in transphosphorylation of JAK kinases, which then leads to phosphorylation of STAT proteins. ${ }^{30-34}$ Phosphorylation of STAT proteins on tyrosine residues leads to STAT homo- or heterodimerization, translocation from the cytoplasm to the nucleus, and binding to specific DNA elements (STAT recognition sites) to regulate target gene expression. ${ }^{31,32,35}$

Such an element is found in the ICER promoter, and we have shown that PSTAT3 association with this site is enhanced after SE in the DG. ${ }^{22}$ Furthermore, siRNA knockdown of STAT3 inhibits BDNF-induced ICER, as does blockade of the JAK-STAT signaling pathway with pyridone 6 in primary hippocampal cultures. Most importantly, pyridone 6 administration in vivo into the DG prior to SE blocks both ICER induction and decreased transcription of GABRA1. ${ }^{22}$ These findings suggest that the interplay of the CREB, JAK-STAT, and BDNF signaling pathways are critical for the decrease in $\alpha 1$-subunit levels that occurs in response to SE and that these pathways may provide novel therapeutic targets for epilepsy. In fact, several drugs that specifically inhibit the activity of JAK2 ${ }^{36,37}$ or block downstream STAT activation $^{38,39}$ have already been identified as potential agents in cancer chemotherapy and are in clinical trials. We are currently testing these agents in primary neuronal cultures to determine whether they may also provide alternative therapy for the future treatment of epilepsy. The relationship of cancer biology to neurobiology has not yet been described, and it will be of value to learn how postmitotic cells of the nervous system use the molecules characteristic of proliferation to modulate their responses to injury.

\section{$\alpha 4$ Subunit regulation}

The $\mathrm{GABA}_{\mathrm{A}}$ receptors that contain $\alpha 4$-subunits have unique pharmacologic properties, such as insensitivity to benzodiazepines and increased sensitivity to zinc blockade. ${ }^{40}$ Receptors containing $\alpha 4$-subunits are most often found with the $\delta$-subunit, rather than the $\gamma$-subunit, in combination with $\alpha \beta$. These $\alpha 4 \beta \delta \mathrm{GABA}_{\mathrm{A}}$ receptors are localized to extrasynaptic sites and contribute to tonic inhibition. A minor population of $\alpha 4 \beta \gamma 2 \mathrm{GABA}_{\mathrm{A}}$ receptors are found within DG synapses, where they are proposed to affect both the rise time and decay of synaptic currents. $^{41}$

In addition to the decrease in $\alpha 1$-subunit expression, there is a marked increase in $\alpha 4$-subunit expression during epileptogenesis in TLE models, which in an increase in the abundance of $\alpha 4 \gamma 2$-containing receptors and a reduction in $\alpha 1 \gamma 2$-containing receptors. ${ }^{22}$ The change in receptor subtype from $\alpha 1 \beta \gamma 2$ to $\alpha 4 \beta \gamma 2$ may contribute to epileptogenesis, in that $\alpha 4$-containing $\mathrm{GABA}_{\mathrm{A}}$ receptors have been shown to desensitize rapidly, especially when assembled with $\beta 3$-subunits. ${ }^{42}$ In addition, GABA $_{\mathrm{A}}$ receptors containing the $\alpha 4$-subunit are very sensitive to zinc blockade, ${ }^{40}$ as is seen in DGCs of epileptic brain. ${ }^{7}$

Our studies have shown that the alteration in $\alpha 4$ levels is transcriptionally mediated via an increase in the expression of the transcription factor early growth response factor 3 (Egr3). ${ }^{15}$ The Egr family consists of four proteins (Egr1, -2, -3, and -4) that share nearly identical zinc finger DNA binding domains and bind to a common Egr response element consensus sequence: GCG T/GGG GCG. ${ }^{43}$ Work in our laboratories has demonstrated induction of Egr family transcription factors after SE, with increases in protein levels of Egr3 and enhanced binding of Egr3 to the GABRA4 promoter in the DG of the hippocampus 24 hours after pilocarpine-induced SE. ${ }^{15}$ Similar to its critical role in decreased expression of $\alpha 1$-containing $\mathrm{GABA}_{\mathrm{A}}$ receptors, BDNF again is the endogenous signal that induces Egr3 synthesis and over- 
expression of $\alpha 4 \mathrm{GABA}_{\mathrm{A}}$ receptors-in this case, however, through different signaling pathways: protein kinase $\mathrm{C}$ and mitogen activated protein kinase (PKCMAPK). ${ }^{29}$ Such findings establish the role of BDNF as a multifunctional stimulator of altered inhibition in the hyperactivated nervous system. (For a schematic presentation, see FIG. 1.)

\section{ALTERATION OF OTHER EPILEPTOGENESIS GENES}

The approach we describe of identifying changes in gene expression during epileptogenesis in critical brain regions, and then examining the functional effect of preventing or augmenting these changes, has been applied to a number of genes.

Galanin is a bioactive compound that coexists with classical neurotransmitters and often inhibits their release. Galanin mediates its action via three types of $G$ protein-linked receptors, GaR1-3. It is abundant in several brain structures, including the hippocampus, where its action is predominantly inhibitory. ${ }^{44}$ In animal models of SE, there is an acute reduction in the levels of galanin in hippocampus. ${ }^{44}$ Galanin injection before induction of SE shortens the duration of $\mathrm{SE},{ }^{44}$ whereas, galanin knock-out mice have an increased propensity to

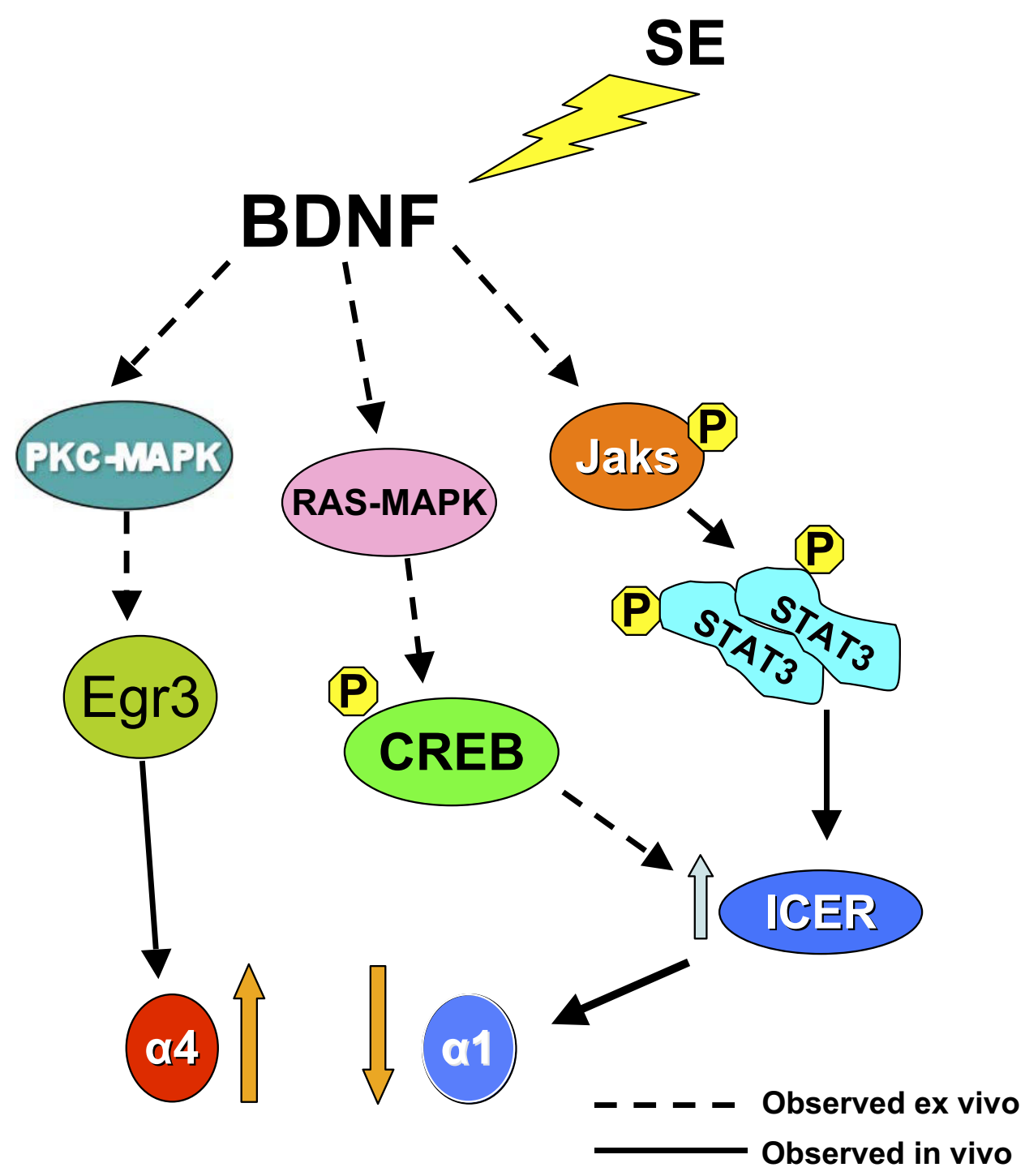

FIG. 1. Differential expression of $\mathrm{GABA}_{\mathrm{A}}$ receptor $\alpha$-subunits via brain-derived neurotrophic factor (BDNF)-stimulated signal transduction pathways. Whether a GABA $A_{A}$ receptor has an $\alpha 1$ - or $\alpha 4$-subunit in its complex may have dramatic effects on brain inhibition. The results of our research show that BDNF may be responsible for flipping the switch in $\alpha$-subunit expression, with decreased $\alpha 1$ and increased $\alpha 4$, all in response to the activities of one signaling molecule, BDNF. Dramatic increases in the levels of BDNF associated with status epilepticus (SE) may drive distinct changes in gene expression through activation of at least three pathways: protein kinase C-mitogen activated protein kinase (PKC-MAPK); RAS-MAPK; and Janus kinase-signal transducer and activator of transcription (JAKSTAT). CREB = cAMP-responsive element binding protein; Egr3 = early growth response factor 3; ICER = inducible cAMP early repressor; $\mathrm{P}=$ phosphate. Evidence to support this model comes from a variety of in vitro, ex vivo, and in vivo studies (as discussed in the text). 
develop SE. ${ }^{45}$ Using a gene therapy approach, Haberman et al. $^{46}$ showed that injection of AAV containing coding sequence for active galanin peptide into inferior collicular cortex increased the threshold for seizure generation to electrical stimulation. A recent study by KanterSchlifke et al. ${ }^{47}$ showed that overexpression of galanin by injection of AAV containing a galanin gene in hippocampus decreased duration of afterdischarges and increased the latency to develop generalized seizures in the kindling model of epilepsy. A more direct approach to increasing the activity of galanin is to use galanin receptor agonists that can cross the blood-brain barrier. Galnon, a low molecular weight (677 Da) galanin receptor ligand, has been shown to affect various physiological as well as pathological functions. ${ }^{48}$ Galnon has been shown to have anticonvulsant activity in the pentylenetetrazolinduced seizure model: galnon injection reduced the seizure score and increased the seizure latency. ${ }^{49}$

Neuropeptide Y (NPY) has been associated with a number of biologically important functions, such as learning and memory. Neuropeptide $\mathrm{Y}$ mediates its action through six receptors (Y1-6) that belong to the G-protein coupled superfamily. In a number of studies conducted in different animal models of epilepsy, an increase in NPY expression in the mossy fiber pathway of the hippocampus was observed, suggesting a modulatory role of NPY in epileptic activity. ${ }^{50}$ Furthermore, mice that lack NPY have a reduced threshold for developing seizures with pentylenetetrazol and also develop spontaneous seizures. ${ }^{51} \mathrm{~A}$ recent study by Noé et al. ${ }^{52}$ showed that AAV containing an NYP gene injected in rats 14 weeks after SE induction halted the progression of seizure activity.

Adenosine is an inhibitory modulator that mediates it action through four $G$-protein coupled receptors: $A_{1}$, $A_{2 A}, A_{2 B}$, and $A_{3}$. Decreased adenosine levels ${ }^{53}$ and long-term reduction in $A_{1}$ receptors ${ }^{54}$ have been observed in different animal models of epileptogenesis. Adenosine antagonists have been shown to reduce the threshold for seizure development. ${ }^{53}$ In the hippocampal kindling model of epilepsy, implantation in rats with myoblast grafts engineered to release adenosine by inhibiting adenosine kinase (an enzyme that converts adenosine to adenosine $3^{\prime}, 5^{\prime}$-monophosphate) reduced seizure duration for 3 weeks after transplantation. ${ }^{55} \mathrm{Sim}$ ilarly, implantation of human mesenchymal stem cells transduced with lentivirus containing RNAi against adenosine kinase in the hippocampus of mice resulted in a $35 \%$ reduction in seizure duration after kainic acid injection, compared with control mice that were implanted with scrambled control sequence. ${ }^{56}$ In another recent study, Wilz et al. ${ }^{57}$ showed that adenosine released from implants over a period of 14 days inhibited development of epilepsy in the kindling model. These studies provide a strong rationale for use of adenosine augmentation as a therapy for intractable epilepsy.

Glial cell line-derived neurotrophic factor (GDNF), a member of the GDNF family of ligands, ${ }^{58}$ has been shown to increase after seizures, ${ }^{59}$ and intraventricular infusion of GDNF has been shown to suppress seizures in various animal models of epilepsy. ${ }^{60,61}$ A recent study by Kanter-Schlifke et al. ${ }^{62}$ showed that overexpression of GDNF using recombinant adeno-associated viral (rAAV) vector suppressed generalized seizure activity but could not prevent kindling epileptogenesis.

\section{CONCLUSION}

The full range of gene expression changes that are involved in epileptogenesis and the molecular mechanisms that underlie them are just beginning to be characterized. Studies in animal models suggest that modulation of the expression of a number of these genes via viral-mediated overexpression or manipulation of their upstream regulation may be useful therapeutic tools for the future treatment of epilepsy.

The transcription factors discussed in this review likely compose only a part of the cascade of signaling events that are initiated by seizures, but it is clear that the BDNF, JAK-STAT, CREB-ICER, and Egr3 signaling pathways play important roles. Recent work characterizing their functions in $\mathrm{GABA}_{\mathrm{A}}$ receptor $\alpha 1$ - and $\alpha 4$ subunit changes in the DG after SE provides important leads for future development of molecular therapies aimed at restoring the balance of excitation and inhibition in the nervous system. Nonetheless, the upstream components of these pathways, and the exact means through which they confer vulnerability to epilepsy, must be further elucidated. Furthermore, because these pathways regulate a myriad of genes with diverse functions, modulation of any of these pathways may have a multitude of downstream effects, many of which may involve cell- and region-specific responses throughout the brain. Therefore, the final effects of pathway blockade on epileptogenesis may be difficult to predict.

For example, although the enhanced $\mathrm{GABA}_{\mathrm{A}}$ receptor $\alpha 1$-subunit expression in the DG that results from JAKSTAT pathway blockade and subsequent ICER inhibition would be expected to have an antiepileptic effect, mutant mice lacking ICER have accelerated kindling ${ }^{63}$ and develop more severe epilepsy after pilocarpine-induced SE. ${ }^{64}$ Consistent with this finding, ICER-overexpressing mice show retardation of kindling development. ${ }^{63}$ Whether the effects of acute and transient blockade of ICER upregulation at the time of SE specifically in the hippocampal formation will have a similar effect on epileptogenesis as constitutive under- or overexpression of ICER globally in the brain remains to be determined. Finally, as several of these signaling path- 
ways have been implicated in the regulation of learning, memory and cell survival, the effects of modulation of these pathways on these critical parameters will need to be closely monitored.

Promising data from animal models also support the potential antiepileptic, and possibly antiepileptogenic, effects of altering the expression of several other neuromodulatory compounds, including galanin, neuropeptide $\mathrm{Y}$, and adenosine. Just as with transcription factor modulation, however, there is still much work to be done to determine the methods for optimal treatment, such as when to initiate delivery and how long to treat. Equally important is how much modulation is necessary for treatment efficacy. Given the adaptive nature of the brain to overcome multiple insults, it would not be surprising if we find that small changes in gene expression using these approaches will have marked effects on restoring brain function. However, we are really at the starting gate, because we know little about the long-term effects of such viral delivery on learning, memory, and cell survival. Because all of the signal transduction pathways and neuromodulatory compounds discussed in this review have highly complex effects, affecting a great many receptors and their effector systems, this area of inquiry is particularly promising for new drug delivery targets and novel drug discovery in epilepsy.

\section{REFERENCES}

1. Mehta AK, Ticku MK. An update on $\mathrm{GABA}_{\mathrm{A}}$ receptors. Brain Res Brain Res Rev 1999;29:196-217.

2. Whiting PJ. The GABA-A receptor gene family: new targets for therapeutic intervention. Neurochem Int 1999;34:387-390.

3. Vicini S. Pharmacologic significance of the structural heterogeneity of the $\mathrm{GABA}_{\mathrm{A}}$ receptor-chloride ion channel complex. Neuropsychopharmacology 1991;14:9-15.

4. Laurie DJ, Wisden W, Seeburg PH. The distribution of thirteen $\mathrm{GABA}_{\mathrm{A}}$ receptor subunit mRNAs in the rat brain: III. Embryonic and postnatal development. J Neurosci 1992;12:4151-4172.

5. Wisden W, Laurie DJ, Monyer H, Seeburg PH. The distribution of 13 $\mathrm{GABA}_{\mathrm{A}}$ receptor subunit mRNAs in the rat brain: I. Telencephalon, diencephalon, mesencephalon. J Neurosci 1992;12:1040-1062.

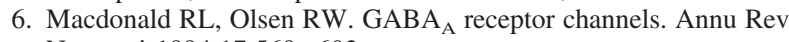
Neurosci 1994;17:569-602.

7. Brooks-Kayal AR, Shumate MD, Jin H, Rikhter TY, Coulter DA. Selective changes in single cell $\mathrm{GABA}_{\mathrm{A}}$ receptor subunit expression and function in temporal lobe epilepsy [Erratum in: Nat Med 1999;5:590]. Nat Med 1998;4:1166-1172.

8. Peng Z, Huang CS, Stell BM, Mody I, Houser CR. Altered expression of the $\delta$ subunit of the $\mathrm{GABA}_{\mathrm{A}}$ receptor in a mouse model of temporal lobe epilepsy. J Neurosci 2004;24:8629-8639.

9. Zhang N, Wei W, Mody I, Houser CR. Altered localization of $\mathrm{GABA}_{\mathrm{A}}$ receptor subunits on dentate granule cell dendrites influences tonic and phasic inhibition in a mouse model of epilepsy. J Neurosci 2007;27:7520-7531.

10. Cohen AS, Lin DD, Quirk GL, Coulter DA. Dentate granule cell $\mathrm{GABA}_{\mathrm{A}}$ receptors in epileptic hippocampus: enhanced synaptic efficacy and altered pharmacology. Eur J Neurosci 2003;17: 1607-1616.

11. Houser CR, Esclapez M. Downregulation of the $\alpha 5$ subunit of the $\mathrm{GABA}_{\mathrm{A}}$ receptor in the pilocarpine model of temporal lobe epilepsy. Hippocampus 2003;13:633-645.

12. Brooks-Kayal AR, Shumate MD, Jin H, et al. Human neuronal $\gamma$-aminobutyric $\operatorname{acid}_{\mathrm{A}}$ receptors: coordinated subunit mRNA ex- pression and functional correlates in individual dentate granule cells. J Neurosci 1999;19:8312-8318.

13. Zhang G, Raol YH, Hsu FC, Coulter DA, Brooks-Kayal AR. Effects of status epilepticus on hippocampal $\mathrm{GABA}_{\mathrm{A}}$ receptors are age-dependent. Neuroscience 2004;125:299-303.

14. Raol YH, Lund IV, Bandyopadhyay S, et al. Enhancing GABA receptor $\alpha 1$ subunit levels in hippocampal dentate gyrus inhibits epilepsy development in an animal model of temporal lobe epilepsy. J Neurosci 2006;26:11342-11346.

15. Roberts DS, Raol YH, Bandyopadhyay S, et al. Egr3 stimulation of GABRA4 promoter activity as a mechanism for seizure-induced up-regulation of $\mathrm{GABA}_{\mathrm{A}}$ receptor $\alpha 4$ subunit expression. Proc Natl Acad Sci U S A 2005;102:11894-11899.

16. Lonze BE, Ginty DD. Function and regulation of CREB family transcription factors in the nervous system. Neuron 2002;35:605623.

17. Jaworski JB, Mioduszewska A, Sánchez-Capelo A, et al. Inducible cAMP early repressor, an endogenous antagonist of cAMP responsive element-binding protein, evokes neuronal apoptosis in vitro. J Neurosci 2003;23:4519-4526.

18. Molina CA, Foulkes NS, Lalli E, Sassone-Corsi P. Inducibility and negative autoregulation of CREM: an alternative promoter directs the expression of ICER, an early response repressor. Cell 1993; $75: 875-886$.

19. Steiger JL, Russek SJ. GABA $A_{A}$ receptors: building the bridge between subunit mRNAs, their promoters, and cognate transcription factors [Erratum in: Pharmacol Ther 2004;103:261]. Pharmacol Ther 2004;101:259-281.

20. Fitzgerald LR, Vaidya VA, Terwilliger RZ, Duman RS. Electroconvulsive seizure increases the expression of CREM (cyclic AMP response element modulator) and ICER (inducible cyclic AMP early repressor) in rat brain. J Neurochem 1996;66:429-432.

21. Lee B, Dziema H, Lee KH, Choi YS, Obrietan K. CRE-mediated transcription and COX-2 expression in the pilocarpine model of status epilepticus. Neurobiol Dis 2007;25:80-91.

22. Lund IV, Hu Y, Raol YH, et al. BDNF selectively regulates $\mathrm{GABA}_{\mathrm{A}}$ receptor transcription by the activation of the JAK/STAT pathway. Science Signal 2008;1(41):ra9.

23. Hu Y, Lund IV, Gravielle MC, Farb DH, Brooks-Kayal AR, Russek SJ. Surface expression of $\mathrm{GABA}_{\mathrm{A}}$ receptors is transcriptionally controlled by the interplay of cAMP-response elementbinding protein and its binding partner inducible cAMP early repressor. J Biol Chem 2008;283:9328-9340.

24. McNamara JO, Huang YZ, Leonard AS. Molecular signaling mechanisms underlying epileptogenesis. Science STKE 2006;(356):re12.

25. Mùdo G, Jiang XH, Timmusk T, Bindoni M, Belluardo N. Change in neurotrophins and their receptor mRNAs in the rat forebrain after status epilepticus induced by pilocarpine. Epilepsia 1996;37: 198-207.

26. Rudge JS, Mather PE, Pasnikowski EM, et al. Endogenous BDNF protein is increased in adult rat hippocampus after a kainic acid induced excitotoxic insult but exogenous BDNF is not neuroprotective. Exp Neurol 1998;149:398-410.

27. Binder DK, Croll SD, Gall CM, Scharfman HE. BDNF and epilepsy: too much of a good thing? Trends Neurosci 2001;24:47-53.

28. Altar CA, Laeng P, Jurata LW, et al. Electroconvulsive seizures regulate gene expression of distinct neurotrophic signaling pathways. J Neurosci 2004;24:2667-2677.

29. Roberts DS, Hu Y, Lund IV, Brooks-Kayal AR, Russek SJ. Brainderived neurotrophic factor (BDNF)-induced synthesis of early growth response factor 3 (Egr3) controls the levels of type A GABA receptor $\alpha 4$ subunits in hippocampal neurons. J Biol Chem 2006;281:29431-29435.

30. Darnell JE Jr, Kerr IM, Stark GR. Jak-STAT pathways and transcriptional activation in response to IFNs and other extracellular signaling proteins. Science 1994;264:1415-1421.

31. Zhong Z, Wen Z, Darnell J. STAT3: a STAT family member activated by tyrosine phosphorylation in response to epidermal growth factor and interleukin-6. Science 1994;264:95-98.

32. Zhong Z, Wen Z, Darnell JE Jr. STAT3 and STAT4: members of the family of signal transducers and activators of transcription. Proc Natl Acad Sci U S A 1994;91:4806-4810. 
33. Schindler C, Darnell JE Jr. Transcriptional responses to polypeptide ligands: the JAK-STAT pathway. Annu Rev Biochem 1995; 64:621-651.

34. Ihle JN. STATs: signal transducers and activators of transcription. Cell 1996;84:331-334.

35. Aaronson DS, Horvath CM. A road map for those who don't know JAK-STAT. Science 2002;296:1653-1655.

36. Dowlati A, Nethery D, Kern JA. Combined inhibition of epidermal growth factor receptor and JAK/STAT pathways results in greater growth inhibition in vitro than single agent therapy. Mol Cancer Ther 2004;3:459-463.

37. Burdelya L, Catlett-Falcone R, Levitzki A, et al. Combination therapy with AG-490 and interleukin 12 achieves greater antitumor effects than either agent alone. Mol Cancer Ther 2002; $1: 893-899$.

38. Amit-Vazina M, Shishodia S, Harris D, et al. Atiprimod blocks STAT3 phosphorylation and induces apoptosis in multiple myeloma cells. Br J Cancer 2005;93:70-80.

39. Faderl S, Ferrajoli A, Harris D, Van Q, Kantarjian HM, Estrov Z. Atiprimod blocks phosphorylation of JAK-STAT and inhibits proliferation of acute myeloid leukemia (AML) cells. Leuk Res 2007; 31:91-95.

40. White G, Gurley D. Alpha subunits influence Zn block of $\gamma 2$

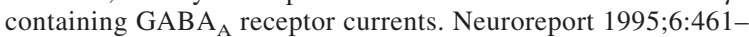
464.

41. Jones-Davis DM, Macdonald RL. GABA receptor function and pharmacology in epilepsy and status epilepticus. Curr Opin Pharmacol 2003;3:12-18.

42. Lagrange AH, Botzolakis EJ, Macdonald RL. Enhanced macroscopic desensitization shapes the response of $\alpha 4$ subtype-containing $\mathrm{GABA}_{\mathrm{A}}$ receptors to synaptic and extrasynaptic GABA. J Physiol 2007;578:655-676.

43. O'Donovan KJ, Tourtellotte WG, Millbrandt J, Baraban JM. The EGR family of transcription-regulatory factors: progress at the interface of molecular and systems neuroscience. Trends Neurosci 1999;22:167-173.

44. Mazarati A, Liu H, Soomets U, et al. Galanin modulation of seizures and seizure modulation of hippocampal galanin in animal models of status epilepticus. J Neurosci 1998;18:10070-10077.

45. Mazarati AM, Hohmann JG, Bacon A, et al. Modulation of hippocampal excitability and seizures by galanin. J Neurosci 2000; 20:6276-6281.

46. Haberman RP, Samulski RJ, McCown TJ. Attenuation of seizures and neuronal death by adeno-associated virus vector galanin expression and secretion. Nat Med 2003;9:1076-1080.

47. Kanter-Schlifke I, Toft Sørensen A, Ledri M, Kuteeva E, Hökfelt T, Kokaia M. Galanin gene transfer curtails generalized seizures in kindled rats without altering hippocampal synaptic plasticity. Neuroscience 2007;150:984-992.

48. Sollenberg U, Bartfai T, Langel U. Galnon: a low-molecular weight ligand of the galanin receptors. Neuropeptides 2005;39: $161-163$
49. Saar K, Mazarati AM, Mahlapuu R, et al. Anticonvulsant activity of a nonpeptide galanin receptor agonist. Proc Natl Acad Sci U S A 2002;99:7136-7141.

50. Nadler JV, Tu B, Timofeeva O, Jiao Y, Herzog H. Neuropeptide Y in the recurrent mossy fiber pathway. Peptides 2007;28:357-364.

51. Erickson JC, Clegg KE, Palmiter RD. Sensitivity to leptin and susceptibility to seizures of mice lacking neuropeptide Y. Nature 1996;381:415-421.

52. Noé F, Pool AH, Nissinen J, et al. Neuropeptide Y gene therapy decreases chronic spontaneous seizures in a rat model of temporal lobe epilepsy. Brain 2008;131:1506-1515.

53. Young D, Dragunow M. Status epilepticus may be caused by loss of adenosine anticonvulsant mechanisms. Neuroscience 1994;58: 245-261.

54. Rebola N, Porciúncula LO, Lopes LV, Oliveira CR, Soares-daSilva P, Cunha RA. Long-term effect of convulsive behavior on the density of adenosine A1 and A2A receptors in the rat cerebral cortex. Epilepsia 2005;46 Suppl 5:159-165.

55. Güttinger M, Padrun V, Pralong WF, Boison D. Seizure suppression and lack of adenosine A1 receptor desensitization after focal long-term delivery of adenosine by encapsulated myoblasts. Exp Neurol 2005;193:53-64.

56. Ren G, Li T, Lan JQ, Wilz A, Simon RP, Boison D. Lentiviral RNAi-induced downregulation of adenosine kinase in human mesenchymal stem cell grafts: a novel perspective for seizure control. Exp Neurol 2007;208:26-37.

57. Wilz A, Pritchard EM, Li T, Lan JQ, Kaplan DL, Boison D. Silk polymer-based adenosine release: therapeutic potential for epilepsy. Biomaterials 2008;29:3609-3616.

58. Saavedra A, Baltazar G, Duarte EP. Driving GDNF expression: the green and the red traffic lights. Prog Neurobiol 2008;86:186-215.

59. Mikuni N, Babb TL, Chakravarty DN, Christi W. Time course of transient expression of GDNF protein in rat granule cells of the bilateral dentate gyri after unilateral intrahippocampal kainic acid injection. Neurosci Lett 1999;262:215-218.

60. Martin D, Miller G, Rosendahl M, Russell DA. Potent inhibitory effects of glial derived neurotrophic factor against kainic acid mediated seizures in the rat. Brain Res 1995;683:172-178.

61. Li S, Xu B, Martin D, Racine RJ, Fahnestock M. Glial cell linederived neurotrophic factor modulates kindling and activationinduced sprouting in hippocampus of adult rats. Exp Neurol 2002; 178:49-58

62. Kanter-Schlifke I, Georgievska B, Kirik D, Kokaia M. Seizure suppression by GDNF gene therapy in animal models of epilepsy. Mol Ther 2007;15:1106-1113.

63. Kojima N, Borlikova G, Sakamoto T, et al. Inducible cAMP early repressor acts as a negative regulator for kindling epileptogenesis and long-term fear memory. J Neurosci 2008;28:6459-6472.

64. Porter BE, Lund IV, Varodayan FP, Wallace RW, Blendy JA. The role of transcription factors cyclic-AMP responsive element modulator (CREM) and inducible cyclic-AMP early repressor (ICER) in epileptogenesis. Neuroscience 2008;152:829-836. 